\title{
Non-financial Reporting Challenges in Monitoring SDG's Achievement: Investment Aspects for Transition Economy
}

\author{
Submitted 20/11/19, $1^{\text {st }}$ revision 03/12/19, $2^{\text {nd }}$ revision 12/01/20 accepted 01/02/20
}

\begin{abstract}
Yuliia Kornieieva ${ }^{1}$
Abstract:

Purpose: The purpose of the article is to reveal and deepen the investment aspects of the methodology for monitoring the achievement of Sustainable Development Goals (SDG`s) in transition countries.

Design/Methodology/Approach: The methodological approach of the paper is based on comparative analysis of core investment indicators proposed by main sustainable reporting initiatives. Conducted analysis helped to identify significant differences in methodological recommendations complicating the process of data comparability for VNR`s compiling purposes.
\end{abstract}

Findings: As a part of SDG 's monitoring process reporting challenges include: the use of so-called "SDG-washing" practices in non-financial reporting; selective presentation of facts through the use of "Cherry-picking" practice in non-financial reporting; the difficulty in measuring progress of the entity's contribution to the achievement of the SDGs on the basis of available indicators in the non-financial reporting; a weak corporate governance culture for reporting as in transition economies; the necessity to develop approaches to assess the materiality of information received for investment purposes.

Practical Implications: Sustainability investment indicators in non-financial reporting requirements today do not reflect investing in cost-effectiveness in the context of evaluating the progress of the SDG's implementation. In order to reveal the entity's attempts to use "SDG-washing" and "Cherry-picking" practices is proposed to include an investment priority ratio to the list of economic indicators.

Originality/Value: The paper contains a methodology for a new non-financial reporting indicator allowing to evaluate the purpose of enterpeise`s capital investments policy.

Keywords: Non-financial reporting, sustainable reporting initiatives, core indicators, Sustainable Development Goals (SDGs), sustainability monitoring, transition economy.

JEL Codes: D82, E01, E22, Q01, Q56.

Paper Type: Research Paper.

\section{Acknowledgments:}

This research were developed by author during participation at post doctoral training programme at Academy of financial management, Kyiv, Ukraine (2017-2019).

\footnotetext{
${ }^{1} \mathrm{PhD}$ in Economics, Senior Research Fellow, Academy of Financial Management, Kyiv, Ukraine, e-mail: korneevaj@ukr.net
} 


\section{Introduction}

By defining "sustainable inclusive economic growth" as a progress in the development of an economic system that allows to maintain a certain standard and quality of life for the long term, we emphasize that the qualitative and quantitative characteristics of sustainable development are ensured on the basis of the balance of social justice, environmental safety of production and economic efficiency. Sustainable development implies a combination of maximizing the profits of business entities, increasing production volumes, increasing GDP and, at the same time, reducing the use of natural resources, lowering harmful for the environment emissions, all these require significant investment resources. The state's role in facilitating these processes is decisive. For transitional economies, the process for implementing the concept of sustainable development is complicated by the specific factors. We will not dwell on all investment SDG`s challenges for transition economies in details in this study, however, we consider it appropriate to develop a classification specifying these factors into three main groups: resource, institutional and reporting challenges.

The challenges of resource provision relate, first and foremost, to factors that significantly limit both private and public investment in the achievement of the SDGs, namely: high deficit of the state budget; low FDI inflows; high lending rates; limited banking system liquidity; the need to strengthen the system of domestic resource mobilization (DRM) through the implementation of measures to counteract capital outflow and the erosion of the tax base. Also, resource factors include loss of human capital as a major factor in the country's sustainable economic development due to increased migration trends in transition countries.

The institutional challenges that hinder the implementation of the concept of sustainable development and the achievement of the SDGs for transitive economies include: low level of maturity of public institutions, and consequently high level of shadow economy and corruption; the necessity for intensification of structural transformations to market-oriented economy; the need to ensure economic diversification from energy-intensive raw materials-oriented industries to high-tech extra value-added industries, which will reduce raw materials exports, improve the environment through the introduction of modern technologies, and at the same time increase national competitiveness; the need of further intensification of the involvement of the national economy into globalization processes by enhancing participation in global value chains.

Sustainability management needs to be integrated into day-to-day business decisionmaking processes, and effective reporting is a strategic tool for attracting investment by ensuring the transparency of business processes that underpins investor confidence and commitment to a particular business entity. Having identified some resource and institutional challenges for achieving sustainable development goals in transitive economies we focus on the details of reporting challenges. 
The introduction of regulatory initiatives in the field of investment support for the implementation of the concept of sustainable development at first stage requires a detailed analysis of the current situation based on real statistics. The process of monitoring SDGs achievement requires the assessment of the entities' contribution. The UN Guidelines to Support Country Reporting on the Sustainable Development Goals, published in 2017, noted that national reporting is the most important factor in the process of Sustainable Development Goals' review (United Nations, 2017). The format of global information exchange involves the unification of reporting, as there is a problem of comparability of indicators through the use of different methodologies.

In the context of strengthening the monitoring of the achievement of sustainable development goals, UN launched an international initiative of exchange of information between countries on a regular basis. Accordingly, the analysis is based on evaluation of progress in the achieving of SDGs at national and subnational levels, which involves the preparation and submission of voluntary national reviews (VNRs) by countries. Governments are actively involved in the UN initiative. According to DESA United Nations Data base in 2016 VNR were presented by 22 countries; in 2017 by 43 countries; in 2018 the number has grown to 46 countries; in 201947 countries; in 202050 countries, including Ukraine are expected to submit VNR (DESA UN Voluntary National Reviews Database).

The UN stresses that access to high-quality, actual and disaggregated data is paramount to the VNR, and therefore recommends governments to use existing national platforms that can contribute to the process of preparing reviews in terms of data analytics (DESA UN Handbook, 2018). Macro-level monitoring information content, which will be displayed in the country's VNR, should be based on the reporting of companies that require data unification, and therefore micro-level data collection unified techniques. Lack of coordination in the national statistical system can be a major source of problems with available data, providing inconsistent and contradictory information.

Micro-level data sources in developed countries are non-financial reporting of the entity, which reflect the entity's contribution to the SDG`s achievement; and is, to some extent, a reputational reporting by its nature. Summarizing the above, it should be noted that the pressing issue for today is how to collect and structure information on entities' SDG following which form the array data for the compilation of VNR in order to ensure their comparability and consistency at the regional, national and intergovernmental levels.

\section{Results and Discussion}

Unclear targets and indicators lead to difficulties in measuring progress. The unification of reporting metadata is the basis for the progress of SDG's implementation, which requires systematic and consistent reporting information. 
Investigating the information asymmetry generated by different approaches to sustainable development reporting, we will compare the investment indicators contained in the UNCTAD Guidance on Core indicators for entity reporting on the contribution towards the attainment of the Sustainable Development Goals (UNCTAD ISAR, 2018) with Global reporting standards prepared by Global Sustainability Standards Board (GRI, 2016) and standards developed by the Sustainability Accounting Standards Board (SASB, 2018). It is worth noting that since the transition from GRI G4 guidelines to GRI standards was completed only on July 1, 2018, both sets of indicators were analysed. Concerning standards developed by SASB, a complete set of 77 industry sustainability accounting standards was released on November 7, 2018. The analysis of core indicators will further eliminate the asymmetry of information provision in order to create conditions for harmonization and comparability of companies in terms of their contribution to the achievement of sustainable development goals. Table 1 provides a summary of the core investment indicators contained in the GRI Standards, the UNCTAD Guidelines and the SASB Standards with fully or partially relevant SDG`s indicators.

Table 1. Core investment indicators for sustainable development reporting

\begin{tabular}{|c|c|c|c|c|c|}
\hline $\begin{array}{l}\text { SDG`s } \\
\text { goal, } \\
\text { target, } \\
\text { indicator }\end{array}$ & $\begin{array}{l}\text { Goal } 10 . \\
\text { Target } 10 . \mathrm{b} . \\
\text { Indicator } \\
\text { 10.b.1 } \\
\text { Goal 9. } \\
\text { Target 9.a. } \\
\text { Indicator } \\
\text { 9.a.1 } \\
\end{array}$ & $\begin{array}{l}\text { Goal } 9 . \\
\text { Target } 9.1 . \\
\text { Indicator } 9.4 \text {. }\end{array}$ & $\begin{array}{l}\text { Goal } 17 . \\
\text { Target } 17.17 \\
\text { Indicator } \\
17.17 .1\end{array}$ & $\begin{array}{l}\text { Goal 7. Target 7.b. } \\
\text { Indicator 7.b.1 } \\
\text { Goal 13. Target } 13.1 \\
\text { Goal 17. Target } \\
\text { 17.7. Indicator } \\
\text { 17.7.1. }\end{array}$ & $\begin{array}{l}\text { Goal } 8 . \text { Task } 8.5 \text {. } \\
\text { Target } 8.8 \text {. Indicator } \\
8.8 .2 \text {. } \\
\text { Goal 10. Target } 10.4 \text {. } \\
\text { Indicator } 10.4 .1 .\end{array}$ \\
\hline $\begin{array}{l}\text { UNCTA } \\
\text { D } \\
\text { Guidanc } \\
\text { e }\end{array}$ & & & $\begin{array}{l}\text { A.3.2. } \\
\text { Community } \\
\text { investments }\end{array}$ & $\begin{array}{l}\text { A.3.1. Green } \\
\text { investments }\end{array}$ & \\
\hline \multirow[t]{2}{*}{$\begin{array}{c}\text { GRI } \\
\text { Standar } \\
\text { d / G4 }\end{array}$} & \multirow{2}{*}{$\begin{array}{l}\text { GRI 201-4 } \\
\text { (G4-EC4) } \\
\text { Financial } \\
\text { assistance } \\
\text { received from } \\
\text { government } \\
\text { (includes } \\
\text { investment } \\
\text { grants) }\end{array}$} & \multirow[t]{2}{*}{$\begin{array}{l}\text { GRI 203-1 } \\
\text { (G4-EC7) } \\
\text { Infrastructure } \\
\text { investments } \\
\text { and services } \\
\text { supported }\end{array}$} & \multirow{2}{*}{$\begin{array}{l}\text { GRI 201-1 } \\
\text { (G4-EC1) } \\
\text { Direct } \\
\text { economic } \\
\text { value } \\
\text { generated and } \\
\text { distributed } \\
\text { (includes } \\
\text { community } \\
\text { investments) }\end{array}$} & $\begin{array}{l}\text { G4-EN31 } \\
\text { Total environmental } \\
\text { protection } \\
\text { expenditures and } \\
\text { investments by type }\end{array}$ & \multirow{2}{*}{$\begin{array}{l}\text { GRI 412-3 (G4-HR1) } \\
\text { Significant investment } \\
\text { agreements and } \\
\text { contracts that include } \\
\text { human rights clauses } \\
\text { or that underwent } \\
\text { human rights } \\
\text { screening }\end{array}$} \\
\hline & & & & $\begin{array}{l}\text { GRI G4 Oil and Gas } \\
\text { Sector Disclosures: } \\
\text { OG2 Total amount } \\
\text { invested in } \\
\text { renewable energy }\end{array}$ & \\
\hline \multirow[t]{2}{*}{$\begin{array}{l}\text { SASB } \\
\text { Standar } \\
\text { ds }\end{array}$} & & \multicolumn{4}{|c|}{$\begin{array}{l}\text { FN-IB-410a.2 (1) Number and (2) total value of investments and loans } \\
\text { incorporating integration of environmental, social, and governance (ESG) factors, } \\
\text { by industry }\end{array}$} \\
\hline & & & & $\begin{array}{l}\text { EM-EP-420a.3. } \\
\text { Amount invested in } \\
\text { renewable energy, } \\
\text { revenue generated } \\
\text { by renewable energy } \\
\text { sales }\end{array}$ & \\
\hline
\end{tabular}

Source: Processing performed by the authors based on Global Reporting Initiative, UNCTAD ISAR Guidance, Sustainability Accounting Standards. 
The GRI Standard contains indicators that reflect aspects of economic performance (the "Economic" category). In the investment sector, it includes indicator 201-1 (G4EC1), which reflects the generated and distributed direct economic value and includes investments in local communities (contributions to charities, NGOs and research institutes (unrelated to the organization's commercial research and development); funds to support community infrastructure, such as recreational facilities; direct costs of social programs, including arts and educational events, school or hospital for workers and their families) (GRI 201: Economic Performance, 2016). The UNCTAD Guide contains an indicator A.3.2., reflecting solely investments in local communities. So we can conclude that the GRI 201-1 (G4-EC1) indicator is broader in content and therefore the data collected from reporting on these indicators cannot be compared.

Indicator GRI 201-4 (G4-EC4) "Financial assistance received from government" includes, among other components, investment grants, research and development grants and other relevant types of grants ) (GRI 201: Economic Performance, 2016). In addition, the GRI contains an Indirect Economic Impact Indicator 203-1 (G4EC7) reflecting "Infrastructure investments and services supported" (GRI 203: Indirect Economic Impacts, 2016). Also GRI contains reporting requirements for significant investment agreements and treaties that include human rights provisions Disclosure 412-3 (G4-HR1) "Significant investment agreements and contracts that include human rights clauses or that underwent human rights screening" (GRI 412: Human Rights Assessment, 2016). UNCTAD guidance and SASB standards do not provide reporting on these aspects.

GRI G4 Oil and Gas Sector Disclosures contain indicator OG2 "Total amount invested in renewable energy" which is consistent with SDG Goal 17 "Strengthen the means of implementation and revitalize the global partnership for sustainable development: Technology" (Target 17.7 "Promote the development, transfer, dissemination and diffusion of environmentally sound technologies to developing countries on favourable terms, including on concessional and preferential terms, as mutually agreed") and reports on total amount invested in renewable energy by type of technology (Global Reporting Initiative, The Oil and Gas Sector Disclosures). Indicator EM-EP-420a.3. proposed by SASB reflects the amount of investment in renewable energy, as well as the revenue from the sale of renewable energy so it is slightly wider than the G4 standard (Sustainability Accounting Standard: Investment banking and brokerage, 2018).

UNCTAD Guidance offers to use Indicator A.3.1. "Green investments" for reporting on investments in environmental projects. Analyses shows that A.3.1. is wider than OG2 which covers only investment in renewable energy, but still does not cover revenues from the sale of renewable energy as SASB EM-EP-420a.3. UNCTAD specify green investment as all costs for investments with main purpose of prevention, reducing and elimination pollution and other forms of environmental 
degradation (UNCTAD ISAR (2018).). Similar content to A.3.1. is specified in indicator of Standard G4 "Total environmental protection expenditures and investments by type" EN31, belonging to the category "Ecology" and reflecting the volume of integrated organizational or technological investments that were made in the context of improving environmental performance. Once the G4 Standards were superseded by the GRI Sustainability Reporting Standards (GRI Standards), the content of G4-EN31 indicator has been incorporated into the following topicspecific Standards as management approach guidance (i.e., this information is no longer required): GRI 103: Management Approach (see 'Guidance for clause 1.7' on page 9); GRI 305: Emissions (see the guidance in Section '1. Management approach disclosures', on page 6); GRI 306: Effluents and Waste (see the guidance in Section '1. Management approach disclosures', on page 5); GRI 307: Environmental Compliance (see the guidance in Section '1. Management approach disclosures', on page 5) (Mapping G4 to the GRI Standards). The proposed SASB indicator FN-IB410a.2, which reflects the amount and total value of investments and loans, including the integration of environmental, social and governance factors (ESG) by industry, can be considered as an analog of EN31 (Sustainability Accounting Standard: Investment banking and brokerage, 2018). However, the social orientation of reporting makes this indicator the most general among considered investment related indicators of sustainable development.

Comparative characteristics of core investment indicators for sustainable development reporting has revealed significant differences in developed methodological recommendations which complicates the process of data comparability compiled by different methods.

\section{Monitoring the Achievement of SDG`s in Ukraine}

It's important to emphasize that non-financial reporting in Ukraine is not obligatory. And as corporate governance culture for non-financial reporting in transition economies is weak, the institutional mechanisms for data collection that combines systematic collection and processing of data on the contribution of economic entities to the achievement of the SDGs needs improvement. For these purposes the government should ensure coordination of national statistical systems to counteract the inconsistency and controversy of data reflecting the achievements of the SDGs. Also the process of assessing the contribution of economic entities to the achievement of the SDGs is complicated by large variety of requirements presented in sustainable development Guidelines which leads to informational asymmetry. So it is important to bring non-financial reporting on national level to a uniform format based on the principles of harmonization and comparability. Also in the context of overcoming information asymmetry and increasing transparency it is important to establish a system for monitoring of compliance and reliability of sustainable development reporting. 
One of the harmful for SDG`s achieving trend is the use of "SDG-washing" practice, which means reporting on positive contributions to global goals and ignoring the significant negative impacts. Another tendency is the use of "Cherry-picking", which involves choosing goals, and targets that are the simplest for the company in terms of implementation and not the one that meets the highest priorities.

UNCTAD's investment indicators (A.3.1, A.3.2) address two aspects of the implementation of the SDG - social and environmental issues. Indicator A.3.1 actually reflects the amount of investment in environmental protection facilities in the context of a withdrawal from the system of stimulation of the technocratic type of economic development (corresponding to a component of sustainable economic growth - environmental safety of operations). The indicator covers investments in the conservation of natural resources (land, subsoil, water, atmospheric air, forest, wildlife, etc.); landscape and other natural complexes; territories and objects of natural reserve fund. The social orientation of investment activity is reflected in Indicator A.3.2 which takes into account investments in the health and life of people. At the same time, the Guidelines does not reflect investment in cost-effectiveness in the context of evaluating the progress of the SDG's implementation, which will allow identification of an entity's attempt to use "SDG-washing" and "Cherrypicking practices".

In this context, in order to overcome the erosion challenge, we propose to include to the list of economic indicators the Investment priorities ratio (IP), which will reflect the proportion of eco-friendly investments in fixed capital (green capital investments) from the total amount of fixed capital investment. Actually green capital investments contribute to improving the environmental performance of the enterprise's activity while fixed capital investments is a component of economic efficiency reflecting economic growth trends, ie the potential for enterprise development through expansion or renewal of production facilities.

$$
I P_{S D G}=\frac{\text { green capital investments }}{\text { fixed capital investments }} * 100 \%
$$

$I P_{S D G^{-}}$Investment priorities sustainable development ratio (IP).

Consequently, the proposed indicator reflects whether the upgrade of production facilities was aimed at protecting the environment by introducing environmental friendly technologies, or still focus was made on profit maximization strategy. Investigation of changes in this ratio over some period of time can show the progress (or regress) in SDG`s achievement for each economic entity.

Taking into account the availability of sources of information, we propose to supplement the sustainable reporting initiatives with an indicator that will be based on regularly collected data. As an example, we present appropriate for IP metadata in Ukraine. Information on capital investments for environmental protection by types of environmental measures as well as by sources of financing is contained in State 
statistical observations "On environmental expenditures and environmental payments" which are compiled in accordance with the Methodological provisions on the organization of state statistical observation on the expenditures for environmental protection (Order of the State Statistics Committee of Ukraine, December 23, 2011. No. 392). Observations are carried out according to Form No 1environmental costs (annual) "The costs on environmental protection and ecological payments". All available data is presented on official web site of State Statistics Committee of Ukraine. Relevant information is submitted not later than February 28 to the territorial body of the State Statistics Committee by legal entities in such cases if enterprises: 1) have treatment facilities; 2) carry out environmental protection measures; 3) pay charges for negative impact on the environment; 4) perform research works; 5) provide environmental services; 6) engaged in management activities of environmental protection, according to the list determined by the body of national statistics.

Accordingly, reporting on this indicator is advisable to be carried out by sector, namely - for large and medium-sized enterprises, the main economic activity of which relates to the following NACE codes : A) Agriculture, forestry and fisheries; B) Mining and quarrying; C) Manufacturing; D) Supply of electricity, gas, steam and air conditioning; F) Construction (Classification of economic activities DK 009: 2010).

Data for calculating the Investment priority ratio in the part of fixed capital investments are available from State statistical observations on capital investments, construction and investment projects, as well as the financial statements of the enterprise (Order of the State Statistics Committee of Ukraine, November 10, 2008. No. 436).

\section{Conclusions and Recommendations}

Non-financial reporting challenges in monitoring SDGs achievement for transition economies include:

$\checkmark$ lack of clear reporting requirements in the sphere of sustainable development, which complicates the processes of assessing the contribution of economic entities to the achievement of the SDGs;

$\checkmark \quad$ the need to establish a system for monitoring of compliance and reliability of sustainable development reporting data in the context of overcoming information asymmetry and increasing transparency;

$\checkmark$ the necessity to develop approaches to assessing the materiality of information received for investment purposes in the context of the formation of data relevant for investment decision making process.

$\checkmark \quad$ weak corporate governance culture for reporting in transition economies (company accounting policies); 
$\checkmark$ improvement of institutional mechanisms for data collection that combines systematic collection and processing of data on the contribution of economic entities to the achievement of the SDGs;

$\checkmark$ the need to ensure coordination of national statistical systems to counteract the inconsistency and controversy of data reflecting the achievements of the SDGs;

$\checkmark$ bringing of non-financial reporting to a uniform format based on the principles of harmonization and comparability;

$\checkmark$ the use of so-called "SDG-washing" practices in non-financial reporting;

$\checkmark$ selective presentation of facts through use of "Cherry-picking" practice in non-financial reporting;

$\checkmark$ the difficulty in measuring progress of the entity's contribution to the achievement of the SDGs on the basis of available indicators in the non-financial reporting.

In order to prevent information asymmetry in sustainable reporting and with aim of revealing company's attempts to use "SDG-washing" and "Cherry-picking" practices we propose to expand reporting initiatives with Investment priorities sustainable development ratio. Proposed indicator will reflect the share of Fixed Capital Investment contributing to improving the environmental performance of the company (green capital investments) in total amount of Fixed Capital Investment that reflects trends toward economic growth, representing the enterprise's potential development through expansion or renewal of production capacity.

\section{References:}

DESA United Nations. 2019. Voluntary National Reviews Database. Retrieved https://sustainabledevelopment.un.org/vnrs/.

DESA United Nations. 2018. Handbook for preparation of Voluntary National Reviews. https://sustainabledevelopment.un.org/content/documents/20872VNR_hanbook_2019 Edition_v4.pdf.

Global Reporting Initiative. 2019. The Oil and Gas Sector Disclosures. Retrieved https://www.globalreporting.org/Documents/ResourceArchives/GRI-G4-Oil-and-GasSector-Disclosures.pdf.

Global Sustainability Standards Board. 2016. GRI 201: Economic Performance. Retrieved https://www.globalreporting.org/standards/media/1039/gri-201-economicperformance-2016.pdf.

Global Sustainability Standards Board. 2016. GRI 203: Indirect Economic Impacts. Retrieved https://www.globalreporting.org/standards/media/1004/gri-203-indirecteconomic-impacts-2016.pdf.

Global Sustainability Standards Board. 2016. GRI 412: Human Rights Assessment. Retrieved https://www.globalreporting.org/standards/media/1027/gri-412-humanrights-assessment-2016.pdf.

Mapping G4 to the GRI Standards. 2017. Retrieved https://www.globalreporting.org/standards/media/1100/mapping-g4-to-the-gristandards-disclosures-quick-reference.pdf. 
State Statistics Committee of Ukraine. 2019. Expenditures on environmental protection and environmental payments. Retrieved http://ukrstat.gov.ua/metaopus/2019/3 $01 \quad 0003$ 2019.htm.

State Statistics Committee of Ukraine. 2008. Order of the State Statistics Committee of Ukraine. November 10, 2008. No. 436."On approval of the Instruction on filling in forms of state statistical observations N 2-investments (annual) "Capital investments" and N 2-investments (quarterly) "Capital investments" https://zakon.rada.gov.ua/laws/show/z1154-08.

State Statistics Committee of Ukraine. 2010. Order of the State Statistics Committee of Ukraine. October 11, 2010. No. 457. "Classification of economic activities DK 009: 2010,, Retrieved https://zakon.rada.gov.ua/rada/show/vb457609-10.

State Statistics Committee of Ukraine. 2011. Order of the State Statistics Committee of December 23, 2011 No. 392."Methodological provisions for the organization of state statistical observation on the expenditures of environmental protection". Retrieved http://www.ukrstat.gov.ua/metod_polog/metod_doc/2015/151/mp_2 B 2015.zip.

Sustainability Accounting Standards Board. 2018. Sustainability Accounting Standard: Investment banking and brokerage. Retrieved https://www.sasb.org/wpcontent/uploads/2018/11/Investment_Banking_Brokerage_Standard 2018.pdf.

Sustainability Accounting Standards Board. 2018. Sustainability Accounting Standard: Oil and Gas - exploration and production. Retrieved https://www.sasb.org/wpcontent/uploads/2018/11/Oil_Gas_Exploration_Production_Standard_2018.pdf.

UNCTAD ISAR. 2018. Guidance on Core indicators for entity reporting on the contribution towards the attainment of the Sustainable Development Goals. Retrieved https://isar.unctad.org/wp-content/uploads/2018/10/Guidance-on-CoreIndicator_ISAR-35.pdf.

United Nations. 2017. Guidelines to Support Country Reporting on the Sustainable Development Goals. Retrieved https://unsdg.un.org/resources/guidelines-supportcountry-reporting-sustainable-development-goals. 